\title{
Phenotype of the 22q11.2 deletion in individuals identified through an affected relative: Cast a wide FISHing net!
}

Donna M. McDonald-McGinn, MS, CGC $C^{1}$, Melissa K. Tonnesen, $B S^{1}$, Ayala Laufer-Cahana, $M D^{1}$, Brenda Finucane, MS, $C G C^{2}$, Deborah A. Driscoll, $M D^{1,3}$, Beverly S. Emanuel, PhD ${ }^{1}$, and Elaine H. Zackai, $M D^{1,3}$

\begin{abstract}
Purpose: The chromosome 22q11.2 deletion has been identified in the majority of patients with DiGeorge syndrome, velocardiofacial syndrome, and conotruncal anomaly face syndrome and in some patients with the autosomal dominant Opitz G/BBB syndrome and Cayler cardiofacial syndrome. In addition, 22q11.2 deletion studies are becoming part of a standardized diagnostic workup for some isolated defects such as conotruncal cardiac anomalies and velopharyngeal incompetence. However, there is little information available on the clinical findings of unselected patients. For example, those individuals identified during prenatal diagnosis, as part of a generalized screening protocol, or following the diagnosis in a relative. This information will be invaluable in defining the variability of the disorder and in observing long-term outcome in the absence of targeted remediations. This study allows one to examine the first unselected cohort of patients and serves to highlight the importance of deletion testing in parents of affected probands. Methods: Thirty individuals with a 22q11.2 deletion were identified following the diagnosis in a relative. Nineteen were adults ascertained only following the diagnosis in their child, 10 were children identified following the diagnosis in their sibling, and one was a child diagnosed prenatally following the diagnosis in her parent. Results: Sixty percent of patients had no visceral anomalies. In fact, only 6 of the 19 adults (32\%) and 6 of the 11 children (55\%) had major findings which would have brought them to medical attention. Deletion sizing demonstrated the same large 3-4MB deletion in most families despite wide inter and intrafamilial variability and there was no difference in clinical findings based on the parent of origin. Thus, no genotype-phenotype correlations could be made. Conclusion: We report the first unselected cohort of patients with the 22q11.2 deletion identified through an affected relative. Analysis of this series of 30 patients, many with very mild manifestations of the deletion, allows one to examine the outcome in individuals who lacked specific remediations for this disorder. It emphasizes the importance of broadening the index of suspicion in order to provide appropriate recurrence risk counseling, cognitive remediation, and medical management. Further, it underscores the lack of familial concordance and the current lack of genotype-phenotype correlations in this disorder, and it raises the possibility that the deletion is more common than previously reported. Genetics in Medicine,
\end{abstract} 2001:3(1):23-29.

Key Words: chromosome 22, 22q11.2, DiGeorge syndrome, velocardiofacial syndrome, conotruncal anomaly face syndrome, autosomal dominant Opitz G/BBB syndrome, Cayler cardiofacial syndrome

The 22q11.2 deletion has been identified in the majority of patients with DiGeorge syndrome, velocardiofacial syndrome, and conotruncal anomaly face syndrome, and in some cases of autosomal dominant Opitz G/BBB syndrome and Cayler cardiofacial syndrome. ${ }^{1-9}$ In addition, deletion studies are now

From the ${ }^{1}$ Division of Human Genetics and Molecular Biology, The Children's Hospital of Philadelphia, Philadelphia, Pennsylvania; ${ }^{2}$ Department of Genetics, Elwyn Institute, Elwyn, Pennsylvania; ${ }^{3}$ Department of Obstetrics and Gynecology, The Hospital of the University of Pennsylvania, Philadelphia, Pennsylvania.

Donna M. McDonald-McGinn, MS, CGC, The Children's Hospital of Philadelphia, 34th and Civic Center Boulevard, Philadelphia, PA 19104.

Received: August 16, 2000.

Accepted: October 27, 2000. being performed routinely in the face of solitary findings such as velopharyngeal incompetence, cardiac anomalies, immunodeficiency, hypocalcemia, and learning disabilities or mental retardation. ${ }^{10-17}$

The 22q11.2 deletion is quite possibly one of the most common chromosomal disorders in humans. It has been estimated to range between $1 / 4,000$ to $1 / 10,000$ live births. ${ }^{18-21}$ However, we and others have reported marked phenotypic variability associated with the deletion, and we are in agreement with a recent letter to the editor by Liling et al. suggesting that this variability raises the possibility of patients with "subclinical deletions" being more common than has been previously recognized. ${ }^{10,13,22-24}$ In fact, here we report the first cohort of unselected patients identified with the 22q11.2 deletion only fol- 
lowing the diagnosis in a relative. Their findings shed additional light on the variability of the disorder. They raise the possibility that the deletion is more common than previously reported. They allow us to observe long-term outcome in the absence of targeted remediation. They encourage us to broaden our index of suspicion, and they remind us of the importance of parental testing.

\section{METHODS}

Three hundred and seventy patients with a 22q11.2 deletion were identified through The Children's Hospital of Philadelphia. Seventy-five percent of these patients were residents of the mid-Atlantic states. The remainder were self-referred or had been transferred for cardiac repair from throughout North America and abroad. The majority of patients (62\%) were ascertained through the Clinical Genetics Center/" $22 \mathrm{q}$ and You Center." Of the remainder, 23\% were referred through Cardiology, $7 \%$ from the Cleft Palate Team, and the remainder from Neurology/Child Development (3\%), Immunology/Rheumatology (2\%), ENT (2\%), Endocrinology (0.5\%), and the Feeding Team $(0.5 \%)$. The majority of patients were under the age of 10 years $(72 \%)$. Of whom, $32 \%$ were $<5$ years of age and $40 \%$ were between 5 and 10 years old. Males and females were equally represented. Most patients were Caucasians (79.5\%). This finding likely represents an ascertainment bias, since we've found that within our cohort African American patients lack the typical dysmorphia associated with the deletion. ${ }^{25}$ Eighteen patients (5\%) expired. The average age of death was 7.2 months. Sixteen of these children succumbed to cardiac disease, one died from sepsis, and one expired from an unrelated cause. All patients had confirmed hemizygous deletions of chromosome 22q11.2 using fluorescence in situ hybridization with the commercially available N25 (D22S75) or TUPLE 1 probes. Depending on the age of the patient and their previous clinical workup, individuals underwent a comprehensive multidisciplinary evaluation. This generally included cardiology (including chest x-ray, electrocardiogram, and echocardiogram); child psychology (using the age appropriate standardized measure: Bayley Scales of Infant Development 2nd Edition, Wechsler Preschool and Primary Scales of Intelligence-Revised, Wechsler Intelligence Scale for Children-Third Edition, Wechsler Adult Intelligence Scale-Revised); ENT/Audiology; Genetics; General Pediatrics; Immunology; Plastic Surgery utilizing appropriate instrumentation (nasendoscopy and videoflouroscopy as needed) and Speech Pathology using age appropriate articulation and language measures (i.e., Goldman Fristoe Test of Articulation and the Preschool Language Scale-3). Less frequent evaluations included Dental, Endocrine, the Feeding Team, Gastroenterology, General Surgery, Hematology, Neurology, Neurosurgery, Ophthalmology, Orthopedics, Psychiatry, Rheumatology, and Urology. Typical laboratory studies included a renal ultrasound, immune profile, and ionized calcium. Less frequent studies included endocrine labs (T3, T4, TSH, free T4, IGF1, IGFBP3), a hematologic profile, MRI (brain and/or spine), radiographs (chest, spine, limbs), and a VCUG. Most patients have returned yearly for longitudinal evaluations. Others have only been seen once, some by a limited number of clinicians. Therefore, in all previous reports, as well as here, we break down each clinical subspecialty based on the number of patients evaluated specifically by each discipline.

In this study, 30 individuals were identified only following the diagnosis in a relative. Of these, 19 adults (6 males and 13 females), ranging in age from 20 to 52 years, were diagnosed following the identification of the 22q11.2 deletion in their affected child. In addition, we identified 11 previously undiagnosed children ( 8 males and 3 females) ranging in age from birth to 20 years. Ten were siblings of affected children and one was the offspring of an adult proband. More specifically, five were offspring of affected adults born prior to the identification of the deletion in their sibling and parent. One affected child was born subsequent to the identification of the 22q11.2 deletion in her father and sibling, and one child was the offspring of an adult proband who had come to attention as a teenager in the cleft clinic. The latter two children were both identified prenatally. The remaining four children were diagnosed only following the identification of the deletion in their cotwins.

\section{RESULTS}

Thirty individuals (19 adults and 11 children) were identified with a 22q11.2 deletion following the diagnosis in their relative. Of these patients, $60 \%$ had no visceral anomalies. This included $68 \%$ of adults and $45 \%$ of the children. In looking specifically at the adults, only 6 of the 19 patients (32\%) had come to medical attention prior to the ascertainment in their child (Table 1). Of note, the majority of their proband children had presented with congenital cardiac anomalies. Two parents had overt cleft palate, two had hypocalcemic seizures, one had a laryngeal web, and one carried a diagnosis of schizophrenia.

Table 1

Unselected patients with the 22q11.2 deletion $(N=30)$

\begin{tabular}{lccccccc}
\hline & Overt cleft palate & Congenital heart disease & Hypocalcemic seizures & Laryngeal web & Schizophrenia & VPI and vascular ring & Normal \\
\hline Adults (19) & 2 & 0 & 2 & 1 & 1 & 0 \\
Children (11) & 2 & 3 & 0 & 0 & 0 & 13 \\
\hline
\end{tabular}

VPI, velopharyngeal incompetence. 
None of the adults had congenital cardiac disease. However, one patient was found to have a right aortic arch. The "typical facial dysmorphia" associated with the 22q11.2 deletion was only useful in raising the index of suspicion in some adults with the deletion (Fig. 1). When present, these findings most often included hooded eyelids, a prominent nasal root with a bulbous nasal tip, hypoplastic alae nasae, and auricular anomalies.

Educational history was available for 18 of the 19 adults (Table 2). Sixty-seven percent graduated high school. Of the 12 females: 1 attained an associate's degree in early childhood education; 7 graduated from high school, 2 of whom had a history of requiring learning support; 1 had left high school in the 10th grade; 2 had a history of a learning disability; and 1 received special education. Of the males: 4 graduated high school, 1 of whom required tutorial assistance; 1 had a history of a learning disability; and 1 received special education.

Occupational data were available for 17 of the affected adults (Table 2). Eleven of the 12 females are presently homemakers, and one works in a billing office. Of the 11 homemakers, 1 had previously worked as a cook and 1 as a typist. The paternal occupations included a maintenance worker, chef, farmer, security guard, and milkman.

Of the 11 unselected children, 5 had no visceral anomalies, 3 had congenital heart disease from which 1 expired, 2 had a cleft palate, and 1 had a vascular ring and velopharyngeal incompetence. Like the unselected parents, some but not all children had dysmorphia associated with the 22q11.2 deletion (Fig. 2). Of note, in addition to these 11 children, two siblings had ex-
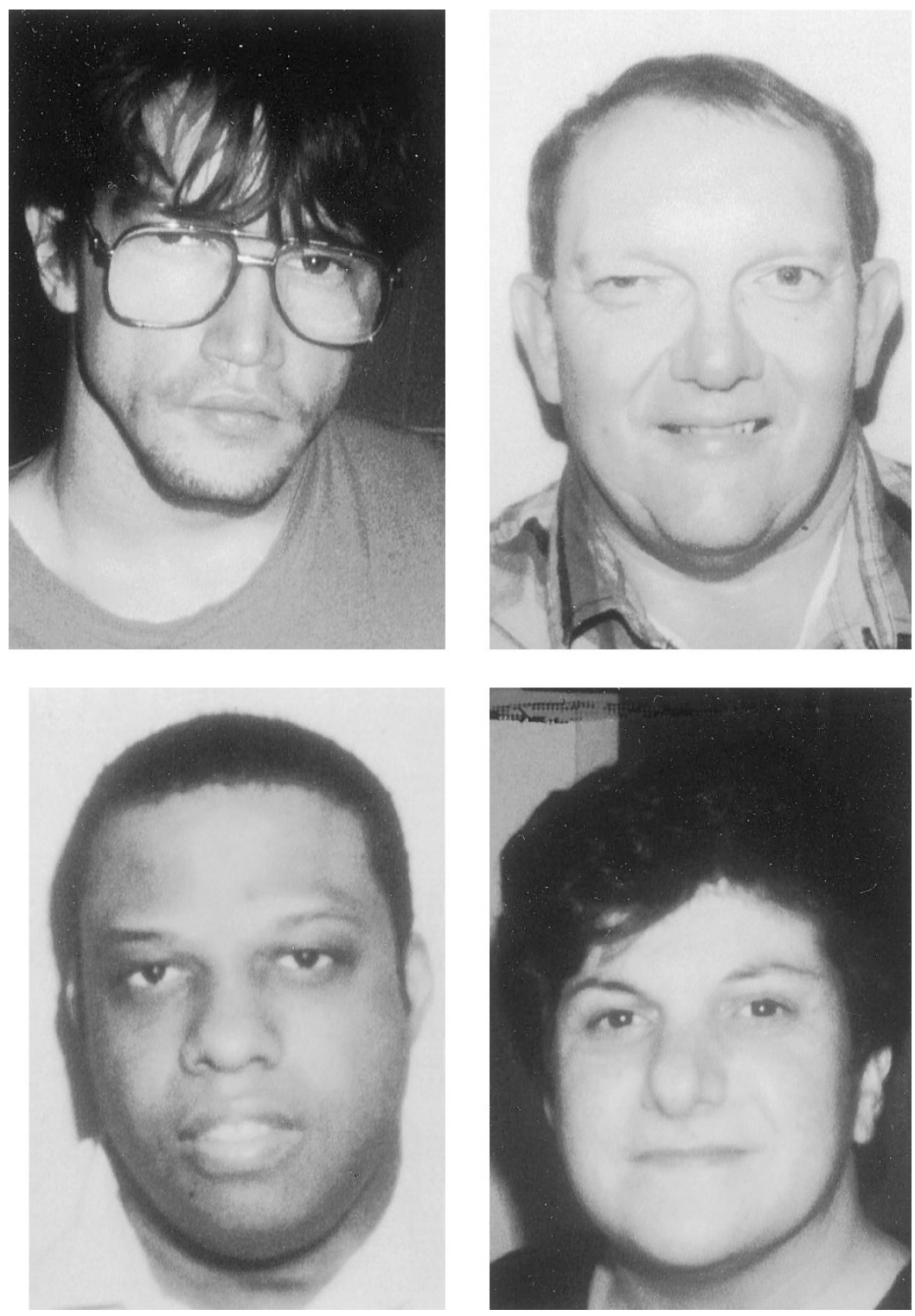

Fig. 1 Four unselected adults with the 22q11.2 deletion demonstrating variability in the facial dysmorphia including hooded eyelids, a bulbous nasal tip, hypoplastic alae nasae, and auricular anomalies in some. 
Table 2

Educational and occupational data on unselected adults

\begin{tabular}{lll}
\hline & \multicolumn{1}{c}{ Males } & \multicolumn{1}{c}{ Females } \\
\hline Educational background $(N=18)$ & Graduated high school (3) & Associate's degree (1) \\
& Graduated high school with tutorial assistance (1) & Graduated high school (5) \\
& Learning disability $(1)$ & Graduated high school with learning disability (2) \\
& Special education $(1)$ & Left high school (1) \\
& & Learning disability (2) \\
Occupational data $(N=17)$ & Maintenance worker & Special education (1) \\
& Chef & Homemakers (11) \\
& Farmer & Insurance billing (1) \\
& Security guard & \\
Milkman & \\
\hline
\end{tabular}
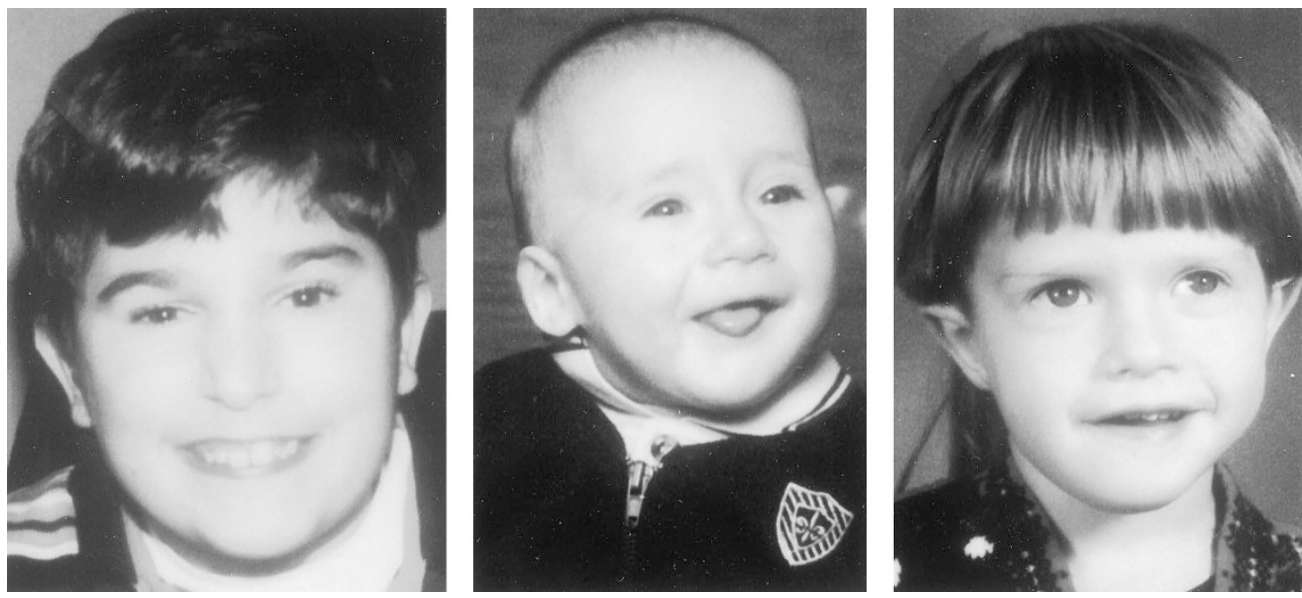

Fig. 2 Three unselected children with variable facial features of the 22q11.2 deletion.

pired prior to the identification of the 22q11.2 deletion in their proband sibling and parent (Families 9 and 12, Fig. 3). One child carried a postmortem diagnosis of DiGeorge syndrome. Findings included truncus arteriosus, thymic aplasia, and absent parathyroids. The second child expired secondary to complications of a neural tube defect, which has been associated with the deletion. ${ }^{26}$

In examining the educational history of these children prior to the diagnosis of the 22q11.2 deletion, we noted that two individuals graduated high school with learning disabilities, one of whom received vocational training, and six school-aged children were attending regular school, two with learning disabilities and four receiving resource room assistance.

In examining the findings within these families and between presumed monozygotic twins, we noted wide variability (Fig. 3). For example, the proband in Family 8 (Fig. 4) was ascertained due to his autism, short stature, and dysmorphic features. The family history was significant for a 12 -year-old sibling with a history of a learning disability. Deletion studies revealed the brother, as well as the father, who was in good health, to be deleted. Similarly, Family 15 (Fig. 5) came to attention following the identification of the 22q11.2 deletion in their child who was seen by genetics at autopsy due to a history of heterotaxia, tracheal agenesis, an atrioventricular canal and mild dysmorphic features consistent with the deletion. These features included a bulbous nasal tip and overfolded helices. During the postmortem parental conference, a paternal history of inguinal hernia, mild scoliosis, and the need for tutorial assistance in high school was obtained. Parental studies subsequently revealed the father to be deleted. Like this father, other unselected individuals in this cohort had minor manifestations of the deletion, including a history of stridor, umbilical hernia, club feet, seizures unrelated to hypocalcemia, and delay in emergence of language.

In an effort to understand this wide inter- and intrafamilial variability molecular studies were examined. The majority of families had the same large 3- to 4-megabase deletion. Three families had a smaller deletion. However, no genotype-phenotype correlations could be made, the deletion size remained the same with vertical transmission, and there was no difference in clinical findings based on the parent of origin. 

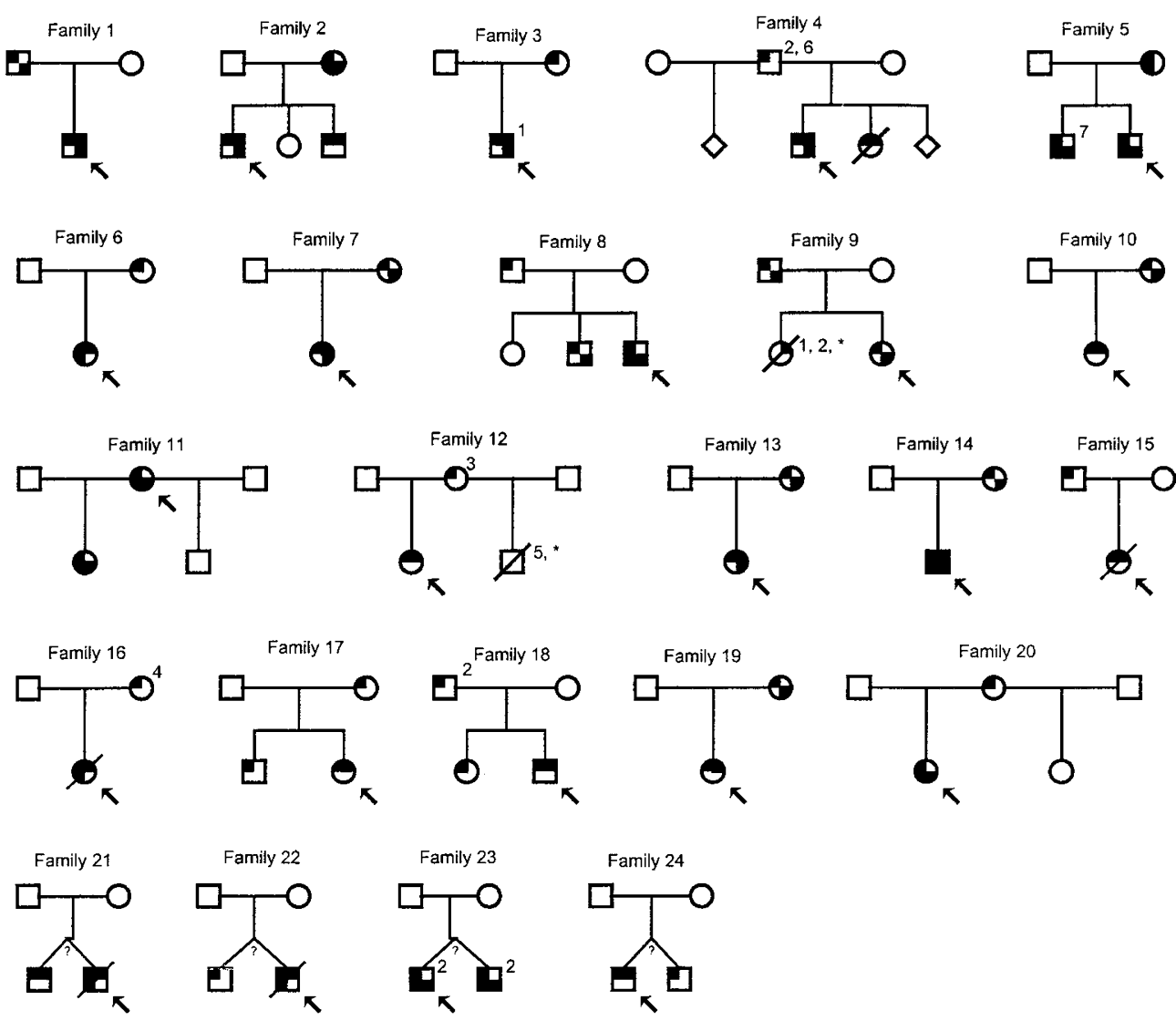
$\square$ Not Affected
[ Learning Disability/
$\square^{4}$ Laryngeal Web
22q11.2 Deletion
$\square^{1}$ immune Deficiency
$\square^{5}$ Neural Tube Defect
Cardiac Defect
$\square^{2}$ Hypocalcemic Seizures
D. Cleft Palate/NPI
$\square^{3}$ Schizophrenia
$\square^{6}$ Right Aortic Arch

$\square$ Deceased prior to deletion studies

Fig. 3 Twenty nuclear families identified with the 22q11.2 deletion in a cohort of 370 patients and 4 sets of presumed monozygotic twins (parental FISH studies were negative but monozygocity studies were not performed). The 30 unselected patients are represented here along with their affected proband child or sibling. Note both interfamilial and intrafamilial variability.
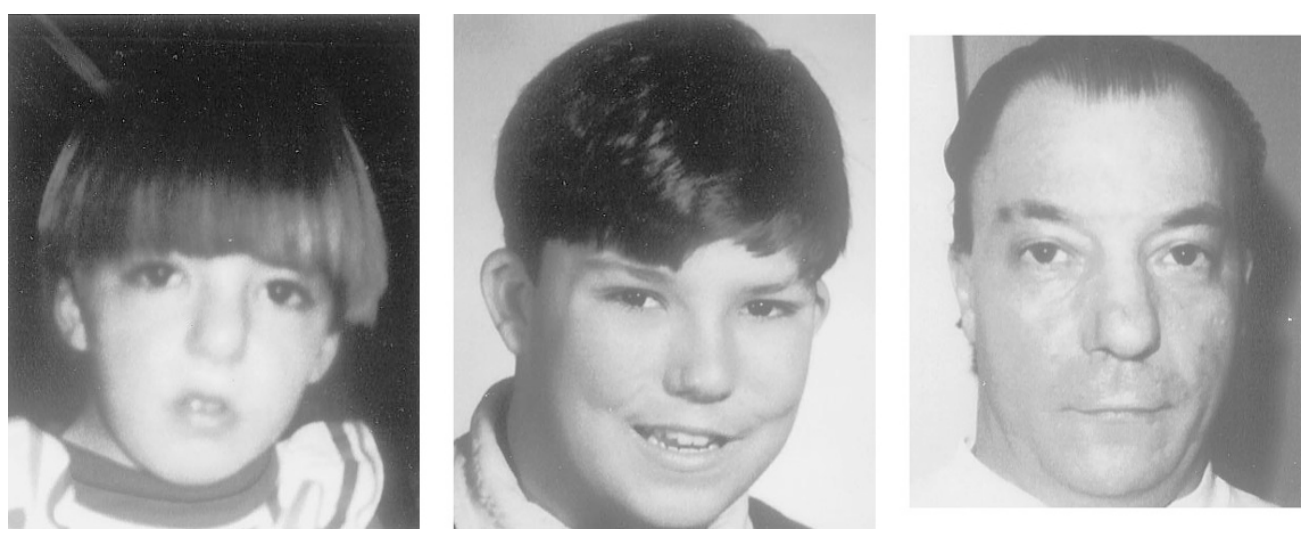

Fig. 4 Family 8. The proband on the left was ascertained via his autism, short stature, and dysmorphic features including epicanthal folds, prominent nasal root, bulbous nasal tip, and hypoplastic alae nasae. His 12-year-old brother (center) had a history of learning difficulty. Note his auricular abnormalities. Their 42 -year-old father (far right) had no medical or education problems. He had minor dysmorphia including a bulbous nasal tip and hypoplastic alae nasae. 

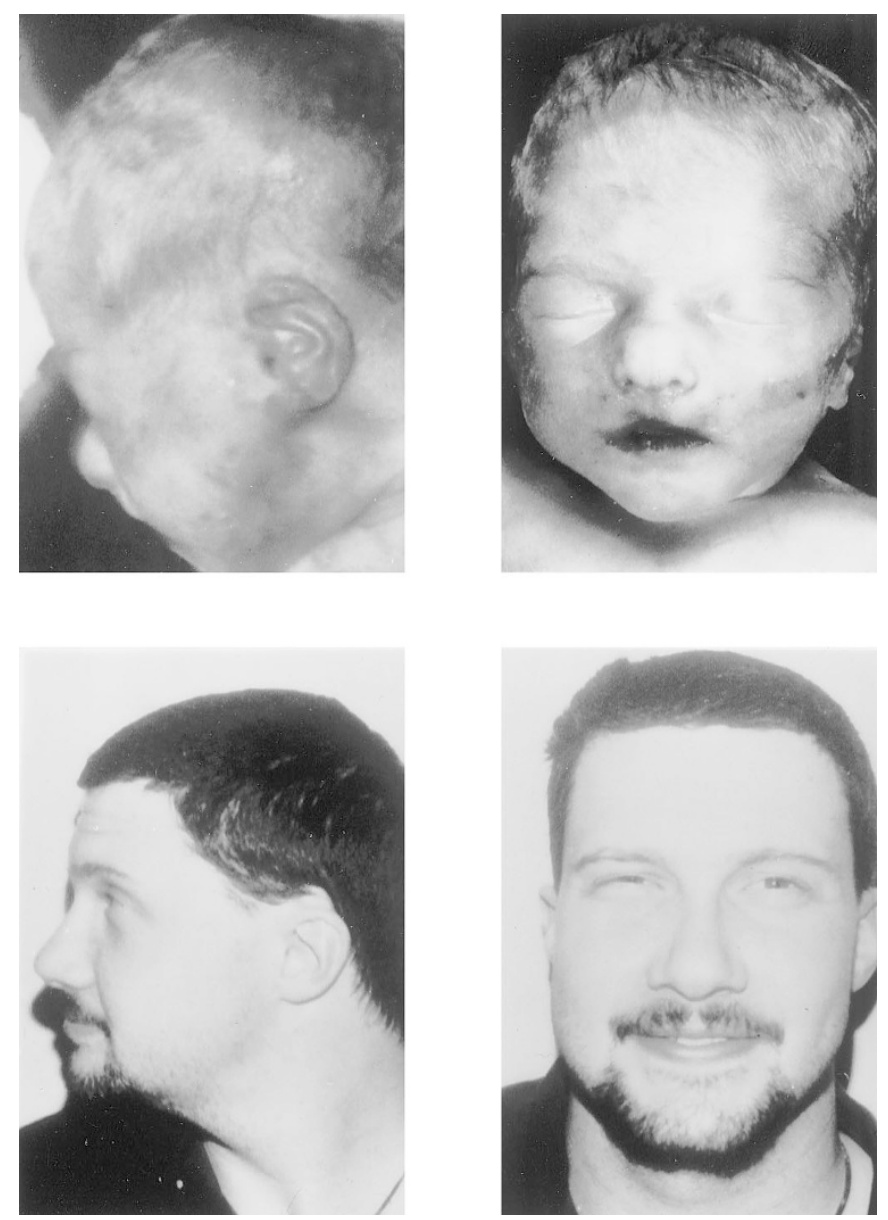

Fig. 5 Family 15. The proband (upper row) was identified at autopsy. Dysmorphic features included a bulbous nasal tip, hypoplastic alae nasae, and thick overfolded helices. The affected father (lower row) was believed to be nondysmorphic.

\section{DISCUSSION}

We report the first group of patients with a 22q11.2 deletion identified solely through an affected relative. This includes the incidence of congenital anomalies, functional abnormalities, such as hypocalcemia and schizophrenia, educational outcome and occupations, where applicable. Most noticeably, there were no adults with congenital cardiac anomalies. This is in stark contrast to the known association of cardiac disease in patients with the deletion. For example, in a subset of our cohort, excluding the unselected individuals reported here, where 301 patients with the 22q11.2 deletion received complete cardiac evaluations, including a chest $\mathrm{x}$-ray, electrocardiogram, and echocardiogram, $75 \%$ were found to have cardiac anomalies. This finding most likely reflects the evolution of palliative cardiac repair in the past 25 years. Furthermore, when we review the overall mortality rate among our group, only $5 \%$ of patients succumb to complications of the deletion. This finding suggests that children with complex cardiac disease due to a 22q11.2 deletion are now unlikely to have reduced reproductive fitness. Thus, in light of the 50\% recurrence risk, this may ultimately lead to an increased incidence of the deletion in the general population.
We also found a paucity of other typical manifestations of the deletion in the 30 unselected patients compared to our larger cohort, most notably palatal anomalies where $61 \%$ of 229 verbal patients had definitive palatal defects and $49 \%$ of 156 patients had confirmed hypocalcemia. These data further support the theory proposed by Liling and colleagues that more patients exist with "subclinical deletions" than has been previously recognized. The educational and occupational data on the 19 unselected adult patients with the 22q11.2 deletion demonstrates the wide variability of cognitive impairments and learning disabilities in this population. In fact, many of the previously unidentified adults had faired relatively well in their respective school settings despite the lack of targeted remediations. Additionally, most were performing well in their occupational settings.

To address the familial incidence of the deletion, we examined the 20 nuclear families within our cohort of 370 patients (Fig. 3). When the number is adjusted to include only probands, these data suggest that the familial incidence of the $22 \mathrm{q} 11.2$ deletion is $6 \%$. However, this number is somewhat flawed in that there were adopted children within our cohort for whom the biological parent was suspect but not available for testing and because we were unable to screen both parents for the deletion in all instances. We were able to study both parents in 147 nuclear families. This would bring the familial incidence up to $14 \%$. However, this number is inflated since we vigilantly pursued parental testing in those families for whom the parent was suspect and were less aggressive in those situations for which the parents had no medical problems or learning issues and for which the reimbursement for the FISH testing was in question. Thus, the true incidence of familial cases is most likely somewhere between these two numbers, approximately $10 \%$.

In summary, the data on the individuals in this series serves to highlight the importance of deletion testing in patients who exhibit minor manifestations of the disorder. It raises the possibility that the deletion is more common than has been previously reported. It underscores the current lack of familial concordance and lack of genotype-phenotype correlations. Furthermore, it emphasizes the need to broaden the index of suspicion, particularly in the parents of affected probands, in order to identify mildly affected individuals with the 22q11.2 deletion which will ultimately lead to appropriate cognitive remediation, medical management, and recurrence risk counseling for these families.

\section{References}

1. Driscoll DA, Budarf ML, Emanuel BS. A genetic etiology for DiGeorge syndrome: consistent deletions and microdeletions of 22q11. Am J Hum Genet 1992;50:924933.

2. Driscoll DA, Spinner NB, Budarf ML, McDonald-McGinn DM, Zackai EH, Goldberg RB, Shprintzen FJ, Saal HM, Zonana J, Jones MC, Mascarello JT, Emanuel BS. Deletions and microdeletions of 22q11.2 in velo-cardio-facial syndrome. Am J Med Genet 1992;44:261-268.

3. Driscoll DA, Salvin J, Sellinger B, McDonald-McGinn D, Zackai EH, Emanuel BS. Prevalence of 22q11 microdeletions in DGS and VCFS; implications for genetic counseling and prenatal diagnosis. J Med Genet 1993;30:813-817. 
4. Burn J, Takao A, Wilson D, Cross I, Momma K, Wadey R, Scambler P, Goodship J Conotruncal anomaly face syndrome is associated with a deletion within chromosome 22. J Med Genet 1993;30:822-824.

5. Matsouka R, Takao A, Kimura M, Imamura S-I, Kondo C, Joh-O K, Ikeda K, Nishibatake M, Ando M, Momma K. Confirmation that the conotruncal anomaly face syndrome is associated with a deletion within 22q11.2. Am J Med Genet 1994;53:285-289.

6. McDonald-McGinn DM, Driscoll DA, Bason L, Christensen K, Lynch D, Sullivan K, Canning D, Zavod W, Quinn N, Rome J, Paris Y, Weinberg P, Clark BJ, Emanuel BS, Zackai EH. Autosomal dominant Opitz GBBB syndrome due to a 22q11.2 deletion. Am J Med Genet 1995;59:103-113.

7. Fryburg JS, Lin KY, Golden EF. Chromosome 22q11.2 deletion in a boy with Opitz oculo-genito-laryngeal syndrome. Am J Med Genet 1996;62:274-275.

8. LaCassie Y, Arriaza MI. Opitz GBBB syndrome and the $22 \mathrm{q} 11.2$ deletion syndrome (Letter). Am J Med Genet 1996;62:318.

9. Giannotti A, Diglio MC, Marino B, Mingarelli R, Dallapiccola B. Cayler cardiofacial syndrome and del 22q11: part of the CATCH22 phenotype. Am J Med Genet 1994;30:807-812.

10. McDonald-McGinn DM, Kirschner R, Goldmuntz E, Sullivan K, Eicher P, Gerdes M, Moss E, Solot C, Wang P, Jacobs I, Handler S, Knightly C, Heher K, Wilson M, Ming JE, Grace K, Driscoll D, Pasquariello P, Randall P, LaRossa D, Emanuel BS, Zackai EH. The Philadelphia story: the 22q11.2 deletion: report on 250 patients. Genet Couns 1999;10:11-24.

11. McDonald-McGinn DM, Driscoll DA, Emanuel BS, Goldmuntz E, Clark BJ III, Solot C, Cohen M, Schultz P, LaRossa D, Randall P, Zackai EH. Detection of 22q11.2 deletion in cardiac patients suggests a risk for velopharyngeal incompetence. $h$ ttp://www.pediatrics.org/cgi/content/full/99/5/e9.

12. Goldmuntz E, Driscoll D, Budarf ML, Zackai EH, McDonald-McGinn DM, Biegel JA, Emanuel BS. Microdeletions of chromosomal region 22q11 in patients with congenital conotruncal cardiac defects. J Med Genet 1993;30:807-812.

13. McDonald-McGinn DM, LaRossa D, Goldmuntz E, Sullivan K, Eicher P, Gerdes M, Moss E, Wang P, Solot C, Schultz P, Lynch D, Bingham P, Keenan G, Weinzimer S, Ming JE, Driscoll D, Clark BJ III, Markowitz R, Cohen A, Moshang T, Pasquariello P, Randall P, Emanuel BS, Zackai EH. The 22q11.2 deletion: screening, diagnostic workup, and outcome of results; report on 181 patients. Genet Test 1997;1:99-108

14. Sullivan KE, Jawad AF, Randall P, Driscoll DA, Emanuel BS, McDonald-McGinn $\mathrm{DM}$, Zackai EH. The frequency and severity of immunodeficiency in chromosome 22q11.2 deletion syndromes (DiGeorge syndrome/velocardiofacial syndrome). Clin Immunol Immunopathol 1998;86:141-146.
15. Moss EM, Batshaw ML, Solot CB, Gerdes M, McDonald-McGinn DM, Driscoll DA, Emanuel BS, Zackai EH, Wang PP. Psychoeducational profile of the 22q11.2 microdeletion: a complex pattern. J Pediatr 1999;134:193-198.

16. Wang P, Solot C, Gerdes M, Moss E, Driscoll D, Emanuel B, McDonald-McGinn DM, Zackai EH. Developmental presentation of 22q11.2 deletion. J Dev Behav Pediatr 1998;19:342-345.

17. Gerdes M, Solot C, Wang PP, Moss E, LaRossa D, Randall P, Goldmuntz E, Clark BJ III, Driscoll DA, Jawad A, Emanuel BS, McDonald-McGinn DM, Batshaw ML, Zackai EH. Cognitive and behavior profile of preschool children with chromosome 22q11.2 deletion. Am J Med Genet 1999;85:127-133.

18. Goodship J, Cross I, LiLing J, Wren C. A population study of chromosome 22q11 deletions in infancy. Arch Dis Child 1998;79:348-351.

19. Devriendt K, Fryns J-P, Mortier G. The annual incidence of DiGeorge/velocardiofacial syndrome. J Med Genet 1998;35:789.

20. Wilson DI, Cross IE, Goodship JA, Brown J, Scambler PJ, Bain HH, Taylor JFN, Walsh K, Bankier A, Burn J, Wolstenholme J. A prospective cytogenetic study of 36 cases of DiGeorge syndrome. Am J Hum Genet 1992;51:957-963.

21. Tezenas Du Montcel S, Mendizabai H, Ayme S, Levy A, Philip N. Prevalence of 22q11 microdeletion. J Med Genet 1996;33:719.

22. Ryan AK, Goodship JA, Wilson DI, Philip N, Levy A, Seidel H, Schuffenhauer S, Oechsler H, Belohradsky B, Prieur M, Aurias A, Raymond FL, Clayton-Smith J, Hatchwell E, McKeown C, Beemer FA, Dallapiccola B, Novelli G, Hurst JA, Ignatius J, Green AJ, Winter RM, Brueton L, Brondum-Nielsen K, Scambler PJ. Spectrum of clinical features associated with interstitial chromosome 22q11 deletions: a European collaborative study. J Med Genet 1997;34:798-804.

23. Wilson DI, Cross IE, Goodship JA, Coulthard S, Carey AH, Scambler PJ, Bain HH, Hunter AS, Carter PE, Burn J. DiGeorge syndrome with isolated aortic coarctation and isolated ventricular septal defect in three sibs with a 22q11 deletion of maternal origin. Br Heart J 1991;66:308-312.

24. Liling J, Cross I, Burn J, Daniel CP, Tawn EJ, Parker L. Frequency and predictive value of 22q11 deletion. J Med Genet 1996;36:794-795.

25. McDonald-McGinn DM, Driscoll DA, Emanuel BS, Zackai EH. The 22q11.2 deletion in African-American patients: an underdiagnosed population. Am J Hum Genet 1996;59:A20.

26. Nickel RE, Magenis RE. Neural tube defects and deletions of 22q11. Am J Med Genet 1996;66:25-27. 